\title{
TU/e EnNHONEN

\section{A numerical method for the solution of time-harmonic Maxwell equations for two-dimensional scatterers}

\section{Citation for published version (APA):}

Pisarenco, M., Maubach, J. M. L., Setija, I. D., \& Mattheij, R. M. M. (2010). A numerical method for the solution of time-harmonic Maxwell equations for two-dimensional scatterers. (CASA-report; Vol. 1047). Technische Universiteit Eindhoven.

\section{Document status and date:}

Published: 01/01/2010

\section{Document Version:}

Publisher's PDF, also known as Version of Record (includes final page, issue and volume numbers)

\section{Please check the document version of this publication:}

- A submitted manuscript is the version of the article upon submission and before peer-review. There can be important differences between the submitted version and the official published version of record. People interested in the research are advised to contact the author for the final version of the publication, or visit the $\mathrm{DOI}$ to the publisher's website.

- The final author version and the galley proof are versions of the publication after peer review.

- The final published version features the final layout of the paper including the volume, issue and page numbers.

Link to publication

\section{General rights}

Copyright and moral rights for the publications made accessible in the public portal are retained by the authors and/or other copyright owners and it is a condition of accessing publications that users recognise and abide by the legal requirements associated with these rights.

- Users may download and print one copy of any publication from the public portal for the purpose of private study or research.

- You may not further distribute the material or use it for any profit-making activity or commercial gain

- You may freely distribute the URL identifying the publication in the public portal.

If the publication is distributed under the terms of Article 25fa of the Dutch Copyright Act, indicated by the "Taverne" license above, please follow below link for the End User Agreement:

www.tue.nl/taverne

Take down policy

If you believe that this document breaches copyright please contact us at:

openaccess@tue.nl

providing details and we will investigate your claim. 


\section{EINDHOVEN UNIVERSITY OF TECHNOLOGY}

Department of Mathematics and Computer Science

\section{CASA-Report IO-47 \\ September 2010}

A numerical method for the solution of time-harmonic

Maxwell equations for two-dimensional scatterers

by

M. Pisarenco, J.M.L. Maubach, I. Setija, R.M.M. Mattheij

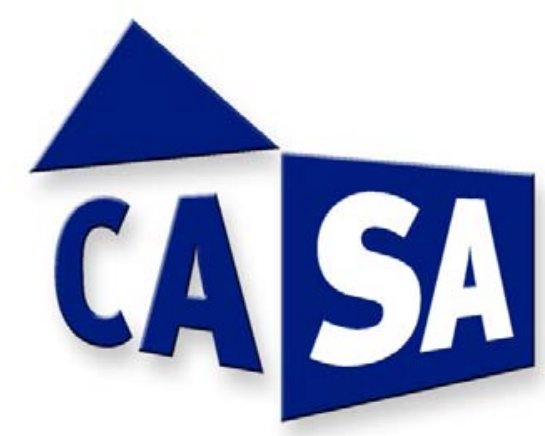

Centre for Analysis, Scientific computing and Applications

Department of Mathematics and Computer Science

Eindhoven University of Technology

P.O. Box 513

5600 MB Eindhoven, The Netherlands

ISSN: 0926-4507 


\title{
A numerical method for the solution of time-harmonic Maxwell equations for two-dimensional scatterers
}

\author{
Maxim Pisarenco*, Joseph Maubach*, Irwan Setija ${ }^{\dagger}$ and Robert Mattheij* \\ * Department of Mathematics and Computer Science, Eindhoven University of Technology, PO Box 513, \\ $5600 M B$ Eindhoven, The Netherlands \\ ${ }^{\dagger}$ Department of Research, ASML Netherlands B.V., De Run 6501, 5504DR Veldhoven, The Netherlands
}

\begin{abstract}
The Fourier modal method (FMM) is a method for efficiently solving Maxwell equations with periodic boundary conditions. In a recent paper [1] the extension of the FMM to non-periodic structures has been demonstrated for a simple two-dimensional rectangular scatterer illuminated by TE-polarized light with a wavevector normal to the third (invariant) dimension. In this paper we present a generalized version of the aperiodic Fourier modal method in contrast-field formulation (aFMM-CFF) which allows arbitrary profiles of the scatterer as well as arbitrary angles of incidence of light.
\end{abstract}

Keywords: Fourier modal method, FMM, aperiodic, aFMM-CFF, perfectly matched layer, PML

PACS: $02.60 . \mathrm{Cb}, 02.60 . \mathrm{Lj}, 02.70 . \mathrm{Dh}$, 42.25.Fx

\section{INTRODUCTION}

The Fourier modal method (FMM), also known under the name of Rigorous Coupled-Wave Analysis (RCWA), originated in the diffractive optics community and was first introduced in [2]. The method has a history of more than three decades marked by considerable improvements on stability [4] and convergence [5, 6, 7]. The monograph [8] gives an overview of the evolution and the implementation of Fourier modal methods. For a mathematical view on the open problems related to the method the reader is referred to [9].

The FMM is an efficient method for solving periodic scattering problems. Its performance is compared to other stateof-the-art numerical methods in [10]. The desire to keep the efficiency advantage of the FMM and allow modeling of aperiodic structures led to the introduction of the aperiodic Fourier modal method in contrast-field formulation (aFMM-CFF) [1, 11]. This method is based on the classical FMM applied to a set of reformulated equations. The periodic boundary conditions are replaced by radiation conditions with the help of perfectly matched layers (PMLs).

\section{PROBLEM STATEMENT}

We are concerned with solving the time-harmonic Maxwell equations for non-magnetic materials on the domain $(x, y, z) \in[0, \Lambda] \times \mathbb{R} \times \mathbb{R}$.

$$
\begin{aligned}
\nabla \times \mathbf{E}(\mathbf{x}) & =-k_{0} \mathbf{H}(\mathbf{x}), \\
\nabla \times \mathbf{H}(\mathbf{x}) & =-k_{0} \varepsilon(x, z) \mathbf{E}(\mathbf{x}),
\end{aligned}
$$

where $\mathbf{x}=(x, y, z)$ is the position vector, $\mathbf{E}=\left(E_{x}, E_{y}, E_{z}\right)$ is the electric field and $\mathbf{H}=\left(H_{x}, H_{y}, H_{z}\right)$ is the magnetic field scaled by $-i \sqrt{\varepsilon_{0} / \mu_{0}}$. The temporal frequency $\omega$ is incorporated into the constant $k_{0}=\omega \sqrt{\varepsilon_{0} \mu_{0}}$. The electric permittivity $\varepsilon$ is assumed $y$-invariant. See Figure 1 (left) for a sample geometry. The incident field is given by

$$
\mathbf{E}^{i n c}(\mathbf{x})=\mathbf{a} e^{-i \mathbf{k}^{i n c} \cdot \mathbf{x}},
$$

where $\mathbf{k}^{i n c}=\left(k_{x}^{i n c}, k_{y}^{i n c}, k_{z}^{i n c}\right)$ is the wavevector and $\mathbf{a}=\left(a_{x}, a_{y}, a_{z}\right)$ is the amplitude vector. Note that the Maxwell equations require that $\mathbf{k}^{\text {inc }} \cdot \mathbf{a}=0$.

We are looking for a solution of (1) on the stripe $(x, y, z) \in[0, \Lambda] \times \mathbb{R} \times \mathbb{R}$. Two possible boundary conditions (BCs) at $x=0$ and $x=\Lambda$ are considered: periodic BCs and radiation (or transparent) BCs. The periodic case is solved with the classical FMM and the aperiodic case is tackled with the generalized version of the newly proposed aFMM-CFF. 


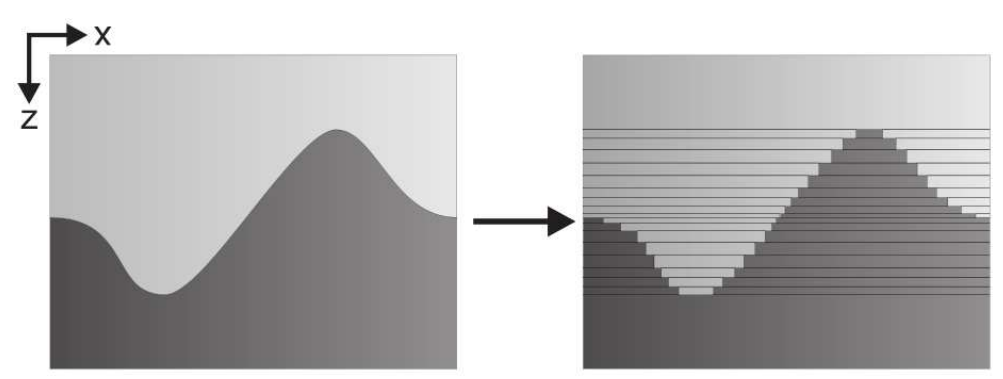

FIGURE 1. Slicing of the scatterer profile

\section{PERIODIC SCATTERER}

The classical FMM is used in order to solve the Maxwell equations for a periodic scatterer. The first step is to divide the computational domain into layers such that the permittivity may be considered $z$-independent in each single layer. Thus, the profile of the scatterer is approximated by a staircase as in Figure 1 . Now in each layer $j=1, \ldots, M$ the permittivity $\varepsilon_{j}(x)$ is independent of $z$ and $y$. This allows elimination of the $y$ and $z$ components of the fields.

$$
\begin{aligned}
& \frac{\partial^{2}}{\partial z^{2}} E_{x, j}(x, y, z)=-\mathfrak{L}_{E, j} E_{x, j}(x, y, z), \quad \text { with } \mathfrak{L}_{E, j}=\frac{\partial^{2}}{\partial y^{2}}+\frac{\partial}{\partial x} \frac{1}{\varepsilon_{j}(x)} \frac{\partial}{\partial x} \varepsilon_{j}(x)+\varepsilon_{j}(x), \\
& \frac{\partial^{2}}{\partial z^{2}} H_{x, j}(x, y, z)=-\mathfrak{L}_{H, j} H_{x, j}(x, y, z), \quad \text { with } \mathfrak{L}_{H, j}=\frac{\partial^{2}}{\partial y^{2}}+\frac{\partial^{2}}{\partial x^{2}}+\varepsilon_{j}(x) .
\end{aligned}
$$

The next step is to discretize the equations in the $x$-direction by using a Galerkin approach with Fourier harmonics as basis functions and test functions,

$$
\phi_{n}(x, y)=e^{-i\left(k_{x n} x+k_{y} y\right)}, \quad \text { where } k_{x n}=k_{x}^{i n c}+n \frac{2 \pi}{\Lambda}, \quad k_{y}=k_{y}^{i n c}, \quad \text { for } n=-N, \ldots,+N .
$$

In each layer the electric and magnetic fields are expanded as

$$
E_{x, j}(x, y, z)=\sum_{n=-N}^{N} s_{j, n}(z) \phi_{n}(x, y), \quad H_{x, j}(x, y, z)=\sum_{n=-N}^{N} u_{j, n}(z) \phi_{n}(x, y) .
$$

The standard inner product on the interval $[0, \Lambda]$ is used. After the application of the Galerkin method, Equations (2) become

$$
\mathbf{s}_{j}^{\prime \prime}(z)=-\mathbf{L}_{s, j} \mathbf{s}_{j}(z), \quad \mathbf{u}_{j}^{\prime \prime}(z)=-\mathbf{L}_{u, j} \mathbf{u}_{j}(z),
$$

with matrices $\mathbf{L}_{s, j}, \mathbf{L}_{u, j} \in \mathbb{R}^{(2 N+1) \times(2 N+1)}$ and vectors $\mathbf{s}_{j}, \mathbf{u}_{j} \in \mathbb{R}^{(2 N+1)}$. These are homogeneous second-order ordinary differential equations whose general solution is given by

$$
\begin{aligned}
\mathbf{s}_{j}(z) & =\mathbf{W}_{s, j}\left(e^{-\mathbf{Q}_{s, j}\left(z-h_{j}\right)} \mathbf{c}_{s, j}^{+}+e^{\mathbf{Q}_{s, j}\left(z-h_{l+1}\right)} \mathbf{c}_{s, j}^{-}\right), \\
\mathbf{u}_{j}(z) & =\mathbf{W}_{u, j}\left(e^{-\mathbf{Q}_{u, j}\left(z-h_{j}\right)} \mathbf{c}_{u, j}^{+}+e^{\mathbf{Q}_{u, j}\left(z-h_{l+1}\right)} \mathbf{c}_{u, j}^{-}\right),
\end{aligned}
$$

where $h_{j}$ is the $z$-coordinate of the top interface of layer $j, \mathbf{W}_{\cdot, j}$ is the matrix of eigenvectors of $\mathbf{L}_{\cdot, j}$ and $\mathbf{Q}_{\cdot, j}$ is a diagonal matrix with square roots of the corresponding eigenvalues on its diagonal.

The vectors $\mathbf{c}_{\cdot, 1}^{+}$and $\mathbf{c}_{,, M}^{-}$are fixed by the incident field and radiation conditions. The remaining vectors $\mathbf{c}_{,, j}^{+}$and $\mathbf{c}_{,, j}^{-}$ are unknown, and can be determined from the interface conditions derived from the Maxwell equations [3].

\section{APERIODIC SCATTERER}

In order to solve the Maxwell equations for an aperiodic scatterer, a generalized version of the aFMM-CFF is used. The periodic basis functions (3) force the solution to be periodic. For an aperiodic scatterer we need to implement 
the radiation $\mathrm{BC}$ at the lateral boundaries. One way of achieving this without changing the basis is to place perfectly matched layers (PMLs) [12] of a certain thickness just before the boundary. This approach has been previously used to apply the FMM to waveguide problems $[13,14,15]$. The PML changes the $x$-derivative in the differential equations (2) as follows

$$
\frac{\partial}{\partial x} \rightarrow \frac{1}{f^{\prime}(x)} \frac{\partial}{\partial x}, \text { with } f(x)=x+i \beta(x) .
$$

The function $\beta(x)$ is continuous and non-zero only in the PMLs which are placed in the stripes $\left[0, x_{l}\right]$ and $\left[x_{r}, \Lambda\right]$. An example of such a function is shown in Figure 2. The operators $\mathfrak{L}_{E, j}$ and $\mathfrak{L}_{H, j}$ with the change of $x$-derivative in (7) will be denoted respectively by $\tilde{\mathfrak{L}}_{E, j}$ and $\tilde{\mathfrak{L}}_{H, j}$.

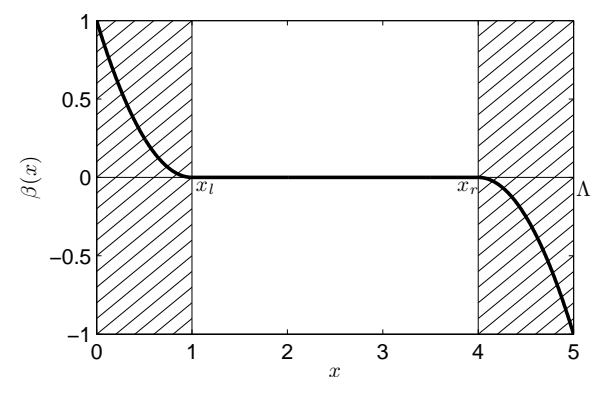

FIGURE 2. Slicing of the scatterer profile

For each field (magnetic and electric) there is a corresponding incident field which is given in advance and which is part of the unknown total field. In order to avoid modifications of the incident field by the PML, the computed solution should consist of only outgoing waves [11]. Therefore the equations are reformulated such that the incident field, i.e. the known part of the solution, is moved into the source. Since the reformulations are similar for both the electric and magnetic field, we demonstrate the derivation only for the former. In addition to the total field problem

$$
\frac{\partial^{2}}{\partial z^{2}} \tilde{E}_{x, j}(\mathbf{x})=-\tilde{\mathfrak{L}}_{E, j} \tilde{E}_{x, j}(\mathbf{x}), \quad E_{x}^{i n c}(\mathbf{x})=a_{x} e^{-i \mathbf{k}^{i n c} \cdot \mathbf{x}}
$$

we define a background problem with PMLs

$$
\frac{\partial^{2}}{\partial z^{2}} \tilde{E}_{x, j}^{b}(\mathbf{x})=-\tilde{\mathfrak{L}}_{E, j}^{b} \tilde{E}_{x, j}^{b}(\mathbf{x}), \quad E_{x}^{b, i n c}(\mathbf{x})=a_{x} e^{-i \mathbf{k}^{i n c} \cdot \mathbf{x}}, \text { where } \tilde{\mathfrak{L}}_{E, j}^{b}=\frac{\partial^{2}}{\partial y^{2}}+\frac{1}{f^{\prime}(x)} \frac{\partial}{\partial x} \frac{1}{f^{\prime}(x)} \frac{1}{\varepsilon_{j}^{b}} \frac{\partial}{\partial x} \varepsilon_{j}^{b}+\varepsilon_{j}^{b}
$$

and a background problem without PMLs

$$
\frac{\partial^{2}}{\partial z^{2}} E_{x, j}^{b}(\mathbf{x})=-\mathfrak{L}_{E, j}^{b} E_{x, j}^{b}(\mathbf{x}), \quad E_{x}^{b, i n c}(\mathbf{x})=a_{x} e^{-i \mathbf{k}^{i n c} \cdot \mathbf{x}}, \text { where } \mathfrak{L}_{E, j}^{b}=\frac{\partial^{2}}{\partial y^{2}}+\frac{\partial}{\partial x} \frac{1}{\varepsilon_{j}^{b}} \frac{\partial}{\partial x} \varepsilon_{j}^{b}+\varepsilon_{j}^{b}
$$

Note that $\varepsilon_{j}^{b}$ is chosen to be $x$-independent, i.e. it represents a multilayer stack. This implies that the background problem without PMLs has an analytical solution. Since the PML effectively implements the radiation conditions, for an ideal PML the two background problems have equal solutions in the physical domain (the region between the PMLs).

$$
\tilde{E}_{x, j}^{b}(\mathbf{x})=E_{x, j}^{b}(\mathbf{x}), \text { for } \mathbf{x} \in\left[x_{l}, x_{r}\right] \times \mathbb{R} \times \mathbb{R}
$$

Subtracting (9) from (8) and defining the contrast field $\tilde{E}^{c}=\tilde{E}-\tilde{E}^{b}$, we get

$$
\frac{\partial^{2}}{\partial z^{2}} \tilde{E}_{x, j}^{c}(\mathbf{x})=-\tilde{\mathfrak{L}}_{E, j} \tilde{E}_{x, j}^{c}(\mathbf{x})-\left(\tilde{\mathfrak{L}}_{E, j}-\tilde{\mathfrak{L}}_{E, j}^{b}\right) \tilde{E}_{x, j}^{b}(\mathbf{x}), \quad E_{x}^{c, i n c}(\mathbf{x})=0 .
$$

The incident field has been removed, and a non-homogeneous term appears on the right-hand side. The background permittivity is chosen such that $\varepsilon(x, z)-\varepsilon^{b}(z)$ vanishes in the PML and has compact support. As a consequence, $\tilde{\mathfrak{L}}_{E, j}-\tilde{\mathfrak{L}}_{E, j}^{b} \neq 0$ only for $x \in\left[x_{l}, x_{r}\right]$, which according to (11) entitles the substitution of $\tilde{E}_{x, j}^{b}(\mathbf{x})$ by $E_{x, j}^{b}(\mathbf{x})$ in (12).

Once the source-term is determined, Equation (12) may be solved. For this purpose, the source term must also be expanded into Fourier modes. After truncation a non-homogeneous system of ordinary differential equations is obtained for each layer. The field is found by matching the general solutions at the layer interfaces. 


\section{NUMERICAL EXAMPLE}

We solve problem (1) on the domain $[0,5] \times \mathbb{R} \times \mathbb{R}$ with the incident field defined by $\left(k_{x}^{i n c}, k_{y}^{\text {inc }}, k_{z}^{\text {inc }}\right)=(0,0,1)$ and $\left(a_{x}, a_{y}, a_{z}\right)=(\sqrt{3} / 2,1 / 2,0)$. In this example the scatterer is a single triangular groove. The permittivity is discretized in the $z$-direction with seven layers, $M=7$. The left plot of Figure 3 shows the sliced geometry which is defined by the refractive index of the material $n(x, z)=\sqrt{\varepsilon(x, z)}$. The PMLs are placed in the stripes $x \in[0,1]$ and $x \in[4,5]$. The right plot of Figure 3 shows the computed magnitude of the $y$-component of the magnetic field.
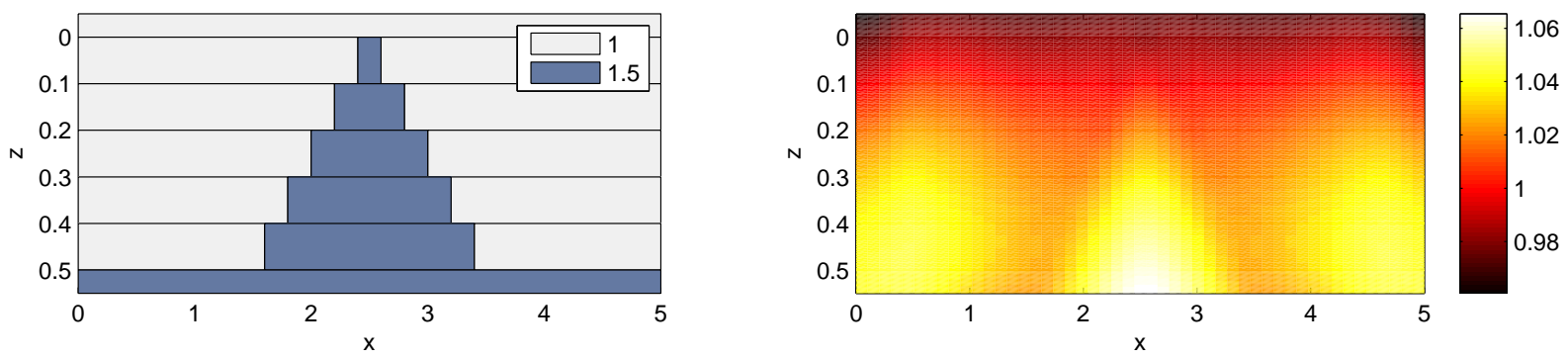

FIGURE 3. Scattering from a single $y$-invariant triangular groove; Geometry of the sliced problem (left) and the computed field $\left|\tilde{H}_{y}(x, y, z)\right|$ at $y=0$ (right).

\section{CONCLUSIONS}

We discussed the application of Fourier modal methods for solving the two-dimensional time-harmonic Maxwell equations numerically. The classical FMM suitable for periodic structures has been formulated based on the Galerkin approach. A generalization of the aFMM-CFF to arbitrary 2D shapes and angles of incidence has been presented.

\section{REFERENCES}

1. M. Pisarenco, J. Maubach, I. Setija, and R. Mattheij, "An extended Fourier modal method for plane-wave scattering from finite structures," SPIE, 2010, vol. 7717.

2. K. Knop, J. Opt. Soc. Am. 68, 1206-1210 (1978), ISSN 0030-3941.

3. M. G. Moharam, E. B. Grann, D. A. Pommet, and T. K. Gaylord, J. Opt. Soc. Am. A 12, 1068-1076 (1995).

4. M. G. Moharam, D. A. Pommet, E. B. Grann, and T. K. Gaylord, J. Opt. Soc. Am. A 12, 1077-1086 (1995).

5. L. Li, J. Opt. Soc. Am. A 13, 1870-1876 (1996).

6. E. Popov, and M. Nevière, J. Opt. Soc. Am. A 17, 1773-1784 (2000).

7. G. Granet, J. Opt. Soc. Am. A 16, 2510-2516 (1999).

8. M. Neviere, and E. Popov, Light Propagation in Periodic Media: Differential Theory and Design (Optical Engineering), CRC, 2002, 1 edn., ISBN 0824708938.

9. J. J. Hench, and Z. Strakoš, ETNA 31, 331-357 (2008).

10. P. Lalanne, M. Besbes, J. P. Hugonin, S. van Haver, O. T. A. Janssen, A. M. Nugrowati, M. Xu, S. F. Pereira, H. Urbach, A. S. van de Nes, P. Bienstman, G. Granet, A. Moreau, S. Helfert, M. Sukharev, T. Seideman, F. Baida, B. Guizal, and D. van Labeke, Journal European Optical Society - Rapid Publications vol 2070222 (2007).

11. M. Pisarenco, J. Maubach, I. Setija, and R. Mattheij, The aperiodic Fourier modal method in contrast-field formulation for simulation of scattering from finite structures, Tech. rep., Technische Universiteit Eindhoven, Eindhoven (2010).

12. J. Berenger, Journal of Computational Physics 114, 185-200 (1994), ISSN 00219991.

13. P. Lalanne, and E. Silberstein, Opt. Lett. 25, 1092-1094 (2000).

14. E. Silberstein, P. Lalanne, J.-P. Hugonin, and Q. Cao, J. Opt. Soc. Am. A 18, 2865-2875 (2001).

15. J. P. Hugonin, and P. Lalanne, J. Opt. Soc. Am. A 22, 1844-1849 (2005). 
PREVIOUS PUBLICATIONS IN THIS SERIES:

\begin{tabular}{|c|c|c|c|}
\hline Number & Author(s) & Title & Month \\
\hline IO-43 & $\begin{array}{l}\text { K. Kumar } \\
\text { T.L. van Noorden } \\
\text { I.S. Pop }\end{array}$ & $\begin{array}{l}\text { Effective dispersion } \\
\text { equations for reactive flows } \\
\text { involving free boundaries } \\
\text { at the micro-scale }\end{array}$ & July 'Io \\
\hline IO-44 & $\begin{array}{l}\text { Y. Fan } \\
\text { I.S. Pop }\end{array}$ & $\begin{array}{l}\text { A class of degenerate } \\
\text { pseudo-parabolic } \\
\text { equations: existence, } \\
\text { uniqueness of weak } \\
\text { solutions, and error } \\
\text { estimates for the Euler- } \\
\text { implicit discretization }\end{array}$ & July 'Io \\
\hline IO- 45 & $\begin{array}{l}\text { M.A.T. van Hinsberg } \\
\text { J.H.M. ten Thije } \\
\text { Boonkkamp } \\
\text { H.J.H. Clercx }\end{array}$ & $\begin{array}{l}\text { An efficient, second order } \\
\text { method for the } \\
\text { approximation of the } \\
\text { Basset history force }\end{array}$ & July 'ıо \\
\hline $10-46$ & $\begin{array}{l}\text { S.S. Antman } \\
\text { D. Bourne }\end{array}$ & $\begin{array}{l}\text { Rotational symmetry vs. } \\
\text { axisymmetry in Shell } \\
\text { theory }\end{array}$ & Sept. 'Io \\
\hline I0-47 & $\begin{array}{l}\text { M. Pisarenco } \\
\text { J.M.L. Maubach } \\
\text { I. Setija } \\
\text { R.M.M. Mattheij }\end{array}$ & $\begin{array}{l}\text { A numerical method for } \\
\text { the solution of time- } \\
\text { harmonic Maxwell } \\
\text { equations for two- } \\
\text { dimensional scatterers }\end{array}$ & Sept. 'IO \\
\hline
\end{tabular}

